http://jmscr.igmpublication.org/home/

ISSN (e)-2347-176x ISSN (p) 2455-0450

crossref DOI: https://dx.doi.org/10.18535/jmscr/v7i11.147

Journal Of Medical Science And Clinical Research

IGM Publication

An official Publication of IGM Publication

\title{
To study the clinical profile of children presenting with history of focal seizure for the first time in OPD/IPD in the pediatric age group of 1-18 years and To study multi detector CT findings in children with focal seizures
}

Authors

\author{
Dr Amar Thakur ${ }^{1 *}$, Dr Ajay Vaid², Dr Milap Sharma ${ }^{3}$, Dr Mohit Bajaj ${ }^{4}$, \\ Dr Swati Mahajan 5 \\ ${ }^{1,2}$ Junior Resident, Department of Pediatrics, DR RPGMC Tanda \\ ${ }^{3}$ Professor, Department of Pediatrics, DR RPGMC Tanda \\ ${ }^{4}$ Pediatrician, Regional Hospital Kullu, HP, ${ }^{5}$ Physician, Regional Hospital Kullu, HP \\ *Corresponding Author \\ Dr Amar Thakur
}

Junior Resident, Department of Pediatrics, DR RPGMC Tanda

\begin{abstract}
Background: Seizure is defined as transient, involuntary alteration of consciousness, behaviour, motor activity, sensation, or autonomic function caused by an excessive rate and hypersynchrony of discharges from a group of cerebral neurons ${ }^{l}$. Partial or focal seizures have specified area of origin. The behavioural manifestations of focal seizures are related not only to the part of the brain involved but also to the maturation of the nervous system and integrity of the pathway necessary for clinical expression. New onset partial seizures in an otherwise asymptomatic child may be idiopathic or symptomatic. Common causes of focal seizures reported in India and developing countries are perinatal insult, gliomas, cortical dysplasias, infarcts, neurocysticercosis (NCC) and tuberculomas ${ }^{2}$. This study was done to find out the clinical profile of focal seizures in pediatric age group and various etiologies related to it.

Methods: It was a hospital based non-interventional prospective study done over a period of one year. All the children 37 were enrolled after meeting inclusion criterias. All the findings were recorded in a pre designed proforma and results were analysed by window SSPE software.

Results: In this study, we enrolled 37 patients. The mean \pm SD age of presentation was 10.43 years ( \pm 4.18 yrs) with a range of 3 - 17 years. Male : female ratio was 1.3:1. 6(16.2\%) cases presented with simple partial seizures while $28(75.7 \%)$ presented with complex partial seizures. Three patients (8.1\%) had focal onset with secondary generalization. Twenty two (59.5\%) had left sided and 15(40.5\%) had right sided seizures. Twenty patients (54.1\%) had more than one episode of seizure prior to being enrolled in the study, 17(45.9\%) patients had a first presentation of focal seizure. Eight (21.6\%) had single episode while 9(24.3\%) had more than multiple episodes of seizures at the time of presentation. an underlying focus of seizure was found in 26(70.2\%) patients. Granuloma, in the form of a ring enhancing lesion was seen in 17(45.9\%) cases while in 3(8.1\%) patients, a structural lesion was seen. There was an area of gliosis in 3(8.1\%) and vascular insult/infarct in 3(8.1\%) patients. CT scan was normal in 11(29.7\%) patients.

Conclusion

- Inflammatory granulomas are the most common cause of partial seizures.

- Neuroimaging is a valuable tool in identifying etiology of focal seizures.

Keywords: Focal, Seizure.
\end{abstract}




\section{Introduction}

Seizures are the most common pediatric neurologic disorders, with $4 \%-10 \%$ of children suffering at least one seizure in the first 16 years of life. Epidemiologic studies reveal that approximately 150,000 children will sustain a first-time, unprovoked seizure each year, and of those, 30,000 will develop epilepsy ${ }^{3}$. Focal seizures are further divided into simple partial seizures and complex partial seizures on the basis of loss of conciousness ${ }^{4}$. Majority of the focal seizures in pediatric population are associated with some underlying cause which can be managed medically and because of this reason this study was undertaken.

\section{Materials}

Study Design: This was a hospital based noninterventional prospective study done at a tertiary care hospital under Department of Pediatrics and Radio-diagnosis.

Study Period: July 2013 to July 2014

\section{Inclusion Criteria}

1. All children between 1-18 years age group presenting with focal seizures or history of focal seizures in past.

\section{Exclusion Criteria}

1. Children with past history of focal seizure already evaluated for the cause.

2. Children with generalized seizures.

After approval from institutional ethical committee, all children in the age group 1-18 years, having any episode of focal seizures not evaluated for underlying cause earlier, presenting during the study period were enrolled in this study after getting informed consent .

A total of thirty seven (37) patients of partial seizures met the inclusion criteria and were included in the study. A detailed history and clinical examination was done in all cases. Children with focal seizures were managed as per protocol and investigated for the etiology of focal seizures with relevant investigations.

All the findings were recorded in a pre designed proforma and results were analysed by window
SSPE software. All these patients were subjected to $\mathrm{CT}$ scan head plain and contrast as and when required and other investigations wherever indicated.

CT scan specifications: CT scan used during the study was multi-detector 16 slides Philips Brilliance. Plain and contrast enhanced images of head were obtained. Contrast medium used in the imaging was non-ionizing Isohexol given intravenously.

Investigations done wherever indicated

- Random Blood Sugar

- Serum Calcium

- Complete Haemogram

- Serum Electrolytes including calcium

- Renal Function Tests

- X-Ray Chest

- Mantoux Test where required

- CT scan head, plain or contrast as indicated per requirement.

- Neurocysticercosis serology wherever required.

\section{Results}

\section{Age distribution}

In this study, we enrolled 37 patients. The mean \pm SD age of presentation was 10.43 years $( \pm 4.18$ yrs) with a range of $3-17$ years.

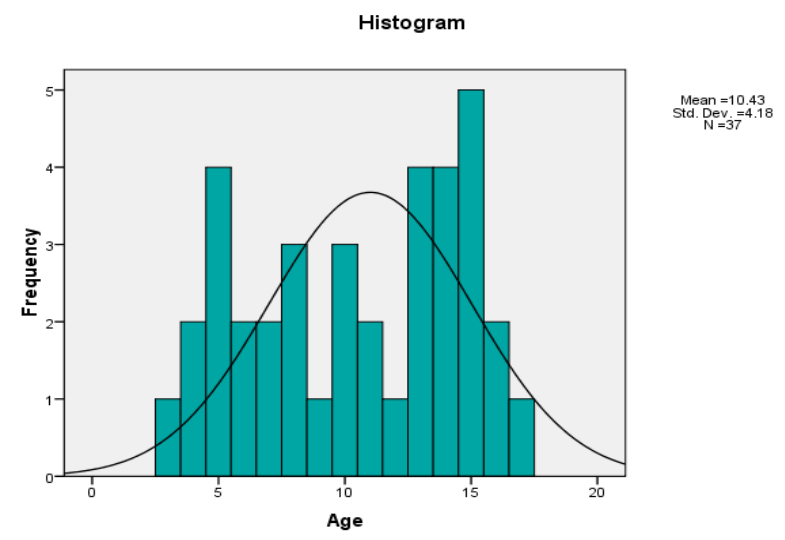

Figure 1: Histogram of age distribution.

Gender Wise distribution:

\begin{tabular}{|l|c|c|}
\hline Sex & No & $\%$ \\
\hline Male & 21 & 56.8 \\
\hline Female & 16 & 43.2 \\
\hline Total & 37 & 100 \\
\hline
\end{tabular}


Type of seizures

\begin{tabular}{|l|c|c|}
\hline Seizures & No & $\%$ \\
\hline Simple partial seizure & 6 & 16.2 \\
\hline Complex partial seizures & 28 & 75.7 \\
\hline $\begin{array}{l}\text { Partial onset with secondary } \\
\text { generalization }\end{array}$ & 3 & 8.1 \\
\hline Total & 37 & 100 \\
\hline
\end{tabular}

\section{Side involved in seizures}

Twenty two (59.5\%) had left sided and $15(40.5 \%)$ had right sided seizures.

\section{Neurological deficit}

Table 3: Showing Todd's palsy association

\begin{tabular}{|l|c|c|}
\hline Neurological deficit & No. & $\%$ \\
\hline Present & 4 & 11 \\
\hline Absent & 33 & 89 \\
\hline Total & 37 & 100 \\
\hline
\end{tabular}

No. of seizures at the time of reporting:

\begin{tabular}{|l|c|c|}
\hline Seizures history & No. & $\%$ \\
\hline Present & 20 & $54.1 \%$ \\
\hline Absent & 17 & $45.9 \%$ \\
\hline Total & 37 & $100 \%$ \\
\hline
\end{tabular}

\section{Frequency of seizures before reporting to our} institute

\begin{tabular}{|l|c|c|}
\hline Frequency of seizures & No. & $\%$ \\
\hline Single episode & 8 & 21.6 \\
\hline 2-5 episodes & 20 & 54.1 \\
\hline More than five episodes & 9 & 24.3 \\
\hline Total & 37 & 100 \\
\hline
\end{tabular}

\section{Family history of seizures}

Only $2(5.4 \%)$ patients had positive family history of seizure and $3(8.1 \%)$ patients had developmental delay in one or more sphere.

\section{Association of seizure with fever}

Only one patient had associated fever at the time of presentation.

\section{Socio economic status}

\begin{tabular}{|l|r|r|}
\hline Socio economic class & No. & $\%$ \\
\hline Class 1 & 0 & 0 \\
\hline Class 2 & 5 & 13.5 \\
\hline Class 3 & 12 & 32.4 \\
\hline Class 4 & 17 & 45.9 \\
\hline Class 5 & 3 & 8.1 \\
\hline Total & 37 & 100 \\
\hline
\end{tabular}

\section{Relation with dietary habit}

Twenty six (70.3\%) studied subjects were consuming mixed diet and 11(29.7\%) were only vegetarian. There is preponderance toward mixed diet consumers.

\section{CT scan head findings in partial seizures}

CT scan was done in all cases and an underlying focus of seizure was found in 26(70.2\%) patients.

Table 7: CT scan findings in partial seizures

\begin{tabular}{|l|c|c|}
\hline CT scan finding & No. & $\%$ \\
\hline Normal & 11 & 29.7 \\
\hline $\begin{array}{l}\text { Ring enhancing lesion/inflammatory } \\
\text { granuloma/ NCC/Tuberculoma }\end{array}$ & 17 & 45.9 \\
\hline Gliosis & 3 & 8.1 \\
\hline Vascular insult/ Infarct & 3 & 8.1 \\
\hline Structural anomaly & 3 & 8.1 \\
\hline Total & 37 & 100 \\
\hline
\end{tabular}

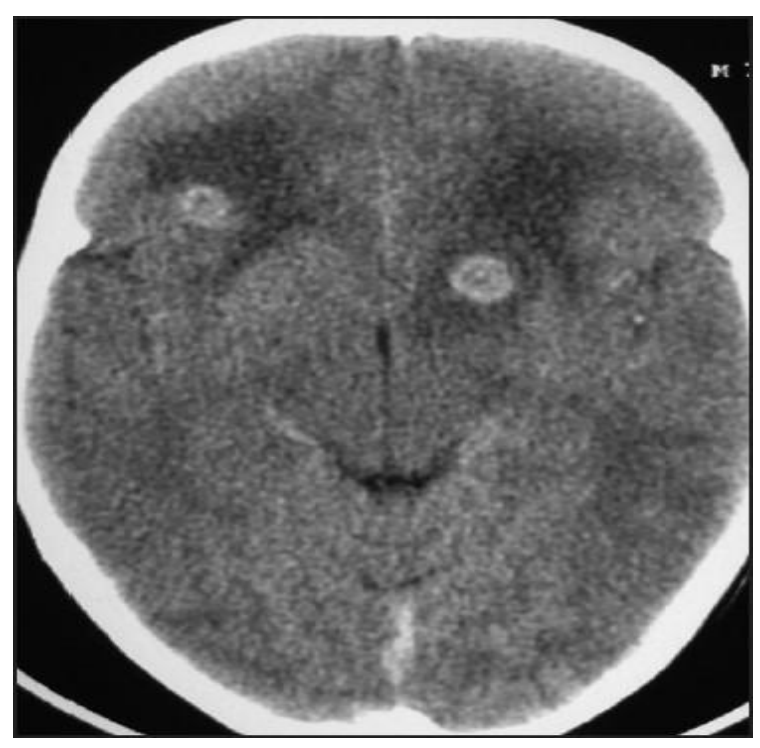

Figure 15: CT scan image of ring enhancing lesion

\section{NCC serology}

Neurocysticercosis serology was carried out only in patient with ring/disc enhancing lesion.

Table 8: NCC serology

\begin{tabular}{|l|c|c|}
\hline Report & No. & Frequency \\
\hline Positive & 8 & $21.6 \%$ \\
\hline Negative & 8 & $21.6 \%$ \\
\hline Equivocal results & 1 & $2.7 \%$ \\
\hline Not done & 20 & $54 \%$ \\
\hline Total & 37 & $100 \%$ \\
\hline
\end{tabular}




\section{Discussion}

In the present study the mean $\pm \mathrm{SD}$ age of presentation was 10.43 years \pm 4.18 years with a range of 3 - 17 years. Bachman et al ${ }^{5}$ who studied 98 children aged 3 months to 20 years also reported mean age of 11 years where as Aggarwal et $\mathrm{al}^{6}$ reported mean age of 6.7 years in a study on children with partial epilepsy. Our study has female predominance with male to female ratio of $1: 1.3$, which is comparable with the study by Puri et $\mathrm{al}^{7}$ having male to female ratio of $1: 1.07$, in that study children with NCC were included.

All children with focal seizures had motor symptoms during seizure activity. In our study, $75.7 \%$ cases had CPS followed by SPS and partial onset with secondary generalization in $16.2 \%$ and $8.1 \%$ patients respectively. A study by Singhi et $\mathrm{al}^{8}$, reported $65 \%$ cases with CPS whereas Aggarwal et $\mathrm{al}^{6}$ reported $51 \%$ and $45 \%$ patients with CPS and SPS respectively. Jain et $\mathrm{al}^{9}$. Seizures are an important cause of morbidity and mortality in childhood which causes great impact on the social as well as economic aspect of the developing and under developed countries. Numerous relatively benign, episodic spells are often misdiagnosed and even treated as seizures. Partial seizures in children represent a large percentage of epilepsy requiring an accurate diagnosis for appropriate and timely management. So in the present study a group of 37 children with partial seizures were included and evaluated for cause of focal seizures.

In the present study the mean $\pm \mathrm{SD}$ age of presentation was 10.43 years \pm 4.18 years with a range of $3-17$ years. Bachman et $a l^{5}$ who studied 98 children aged 3 months to 20 years also reported mean age of 11 years where as Aggarwal et $\mathrm{al}^{6}$ reported mean age of 6.7 years in a study on children with partial epilepsy. Our study has female predominance with male to female ratio of $1: 1.3$, which is comparable with the study by Puri et $\mathrm{al}^{7}$ having male to female ratio of $1: 1.07$, in that study children with NCC were included.

All children with focal seizures had motor symptoms during seizure activity. In our study,
$75.7 \%$ cases had CPS followed by SPS and partial onset with secondary generalization in $16.2 \%$ and $8.1 \%$ patients respectively. A study by Singhi et $\mathrm{al}^{8}$, reported $65 \%$ cases with CPS whereas Aggarwal et al $^{6}$ reported $51 \%$ and $45 \%$ patients with CPS and SPS respectively. Jain et $\mathrm{al}^{9}$ reported $55.23 \%, 22.09$ and $22.67 \%$ children with CPS, SPS and partial onset with secondary generalization respectively.

Fifty nine percent children had right sided focal seizures while $41 \%$ patients had left sided focal seizures which is comparable to the findings by Singhi et $\mathrm{al}^{8}$ study showing right sided in $60 \%$ and left sided in $40 \%$ cases.

Family history of seizures was found in only $2(5.4 \%)$ cases, which were seen in first degree relative and were generalized seizures in all cases. Aggarwal et $\mathrm{al}^{6}$ reported family history in $9.9 \%$ patients with partial seizures.

At the time of examination, $11 \%$ patients had some neurological deficit which is comparable to that observed by Singhi et $\mathrm{al}^{8}$ (14\%). In our study $20(54 \%)$ patients, had history of focal seizures presenting for the first time and they were not evaluated for the cause in past. Rest of the $17(45.9 \%)$ patients had no history of focal seizures. Among the seventeen patients, 8(21.6\%) patients had single focal seizure and $9(24.3 \%)$ had multiple seizures episodes at presentation.

In our study, majority of patients belonged to lower middle and lower socio economic class of modified Kuppuswamy scale ${ }^{10}$. In the studied group, patients of class 3 and class 4 constituted $78 \%$ while class 5 constituted $8 \%$ of the patients. Poor sanitation may be the single most important social factor underlying the increased prevalence of bacterial infection as well as parasitic infestations leading to CNS manifestations in these patients. In an epidemiological study by Hesdorffer DC et $\mathrm{al}^{11}$ in Iceland showed an association between socio economic status and epilepsy in adults not in children and no other study is there based on SE Status. Our study is not based on socioeconomic status, it is a coincidental finding. 
In our study, the etiology of seizures could be determined in $70.3 \%$ cases on the basis of CT scan findings. The commonest abnormality noted was inflammatory ring enhancing lesion in $45.9 \%$ patients. Various studies ${ }^{5,12}$, have shown ring enhancing lesions as the most common CT scan finding in patients with partial seizures in their studies.

On the basis of neuro imaging finding in focal seizures by Singhi et $\mathrm{al}^{8}$ it was found that $25 \%$ cases had ring enhancing lesion, $2 \%$ had cerebral atrophy and $1 \%$ had brain tumour in comparison with our study showing $45.9 \%$ cases with ring enhancing lesion, $8.1 \%$ had vascular insult/infarct, $8.1 \%$ had gliotic change in cerebral cortex and no patient with brain tumour presented to us during study period.

A study by Vibha et $\mathrm{al}^{9}$ showed ring enhancing lesion in $32.5 \%$ and vascular insult/ infarct in $11 \%$ cases, in comparison, in our study $45.9 \%$ cases had REL and $8.1 \%$ cases showed vascular insult/infarct.

In a study by Ramesh et al, ${ }^{13} 23 \%$ cases had cerebral atrophy and 7\% showed REL, $11.5 \%$ had unknown calcification and $3.8 \%$ had a vascular cause. In our study, REL was found in $45.9 \%$ cases and vascular cause in $8.1 \%$ patients.

Imaging results of study by Kapoor $\mathrm{M}$ et $\mathrm{al}^{14}$ showed $30 \%$ REL and $15 \%$ had vascular insult/infarct and cerebral atrophy each whereas the present study revealed ring enhancing lesion in $45.9 \%$ cases, vascular insult /infarct in $8.1 \%$ cases, gliosis in $8.1 \%$ cases and structural anomaly in $8.1 \%$ cases as etiological factor for focal seizures.

In a study done by Misra et $\mathrm{al}^{12} \mathrm{CT}$ scan abnormalities were seen in $79.3 \%$ cases with focal seizures, and the findings included ring enhancing lesions in $63.3 \%$ of cases, calcification of unknown origin in $11.8 \%$ of cases, cerebral atrophy and vascular lesions (infarct and haemorrhage) in 5.9\% and 5.8\% respectively and mass lesions in $4.6 \%$ of cases which is comparable to our study showing abnormalities in $70.2 \%$ cases, with ring enhancing lesions in
$45.9 \%$ patients, gliosis in $8.1 \%$, vascular event in $8.1 \%$ and structural anomalies in $8.1 \%$.

Neurocysticercosis serology was carried out only in patient with ring/disc enhancing lesion. Out of $17(45.9 \%)$ patients with ring enhancing lesion, $8(47 \%)$ had positive serology for NCC.

In our study, ring enhancing lesion was the most common finding on CT scan. Five patients showed multiple ring enhancing lesions in cerebral cortex, all of these had radiological feature suggestive of neurocysticercosis and NCC serology was positive in four of these patients. Twelve patients had a single ring enhancing lesion on CT scan, out of these, four patients were serologically positive for NCC. Three $(8.1 \%)$ patients had gliosis secondary to some CNS injury and $3(8.1 \%)$ patients had intracranial haemorrhage/bleed, while intracranial structural lesions like porencephalic cyst and choroid cyst were found in $3(8.1 \%)$ cases.

On the basis of neuroimaging finding our study is showing ring enhancing lesion as the most common cause of focal seizures which is similar to the studies by Singhi et $\mathrm{al}^{8}$, Vibha et $\mathrm{al}^{9}$, Kapoor et $\mathrm{al}^{14}$, and Misra et $\mathrm{al}^{12}$.

So from this study we can conclude that in developing countries like India computed tomography is a useful, affordable, and easily available investigation modality in patients with focal seizures. However repeated and unnecessary exposures should be avoided keeping in view the fact that no imaging study be done unless there is a clear medical benefit that outweighs any associated risk.

\section{Conclusion}

- Inflammatory granulomas are the most common cause of partial seizures.

- Neuroimaging is a valuable tool in identifying etiology of focal seizures.

- Due to high yielding potential of CT scan in focal seizure, easy availability and affordability, makes it the investigation of choice in focal seizures in developing countries like India. 
- Focal seizures have an underlying cause in $70 \%$ of cases.

- Focal seizures are increasingly present in lower class of Kuppuswamy possibly due to poor hygiene and high prevalence of infection/infestations.

- No patient with partial seizure had intra cranial tumour.

Funding: Nil,

Conflict of interest: None initiated.

\section{Bibliography}

1. Friedman MJ, Sharieff GQ. Seizures in children. Pediatr Clin N Am 2006; 53: 257-77.

2. Singhi $\mathrm{P}$, Singhi S, Ramanathan RP, Bharti S. Neurocysticercosis in focal epilepsy in North India. Epilepsia 1995; 36:156.

3. Blume WT, Luders HO, Mizrahi E, Tassinari C, Van Emde Boas W, Engel J. 2001 Glossary of ictal semiology. Epilepsia42:1212-8.

4. Berg AT, Berkovic SF, Bordie MJ et el. Revised terminology and concepts for organization of seizures and epilepsies:report of ILAE Commission on classification and terminology 2005-2009. Epilepsia 2010; 676-85.

5. Bachman DS, Hodges III FJ, Freeman JM. Computerized axial tomography in chronic seizure disorders of childhood. Pediatrics 1976; 58: 828-32.

6. Aggarwal A, Aneja S, Taluja V, Kumar R, Bhardwaj K. Etiology of partial epilepsy. Indian Pediatr., 1998; 35: 49-52.

7. Puri V, Sharma DK, Kumar S, Choudhary V, Gupta RK, Khalil A. Neurocysticercosis in children. Indian pediatr., 1991; 28(11): 1310-17.
8. Singhi et al, Clinical profile and etiology of focal seizures in North Indian Infants and children, J Epilepsy, 1997: vol10; 1.

9. Neeraj Jain, Vibha Mangal. Role of EEG and CT scan in partial seizures in children. Int. J. Med. Med. Sci. 2011;3(5): 161-3.

10. Ravi kumar BP, Dudala SR, Rao AR. Kuppuswamy's socio economic status scale - a revision of economic parameter for 2012. Intr J Research Dev Health. 2013;1:2-4

11. Hesdorffer DC, Tian H, Anand K, Hauser WA, Ludvigsson P, Olafsson E, Kjartansson O. Socioeconomic status is a risk factor for epilepsy in Icelandic adults but not in children. Epilepsia. 2005; 46 (8): 1297-1303.

12. Misra S, Verma R, Lekhra OP, Mishra NK. CT observations in Partial Seizures. Neurol. India, 1994; 42: 24-7.

13. Ramesh et al. A study of CT and EEG findings in patients with generalized or partial seizures in western Rajasthan. JIACM, 2003;4(1): 24-9. 